\title{
Al-C-Co (Aluminum-Carbon-Cobalt)
}

\section{Raghavan}

The update on this system by [2008Rag] reviewed the experimental results of [1995Kim] and [2006Kim] on Co-rich alloys and presented a liquidus projection, an isothermal section at $1100{ }^{\circ} \mathrm{C}$ and three vertical sections at 3 at.\% C, 10 at.\% $\mathrm{C}$ and 30 at.\% $\mathrm{Al}$ respectively. Recently, [2009Fri] reinvestigated the liquidus surface and proposed some modifications to the results of [1995Kim].

\section{Binary Systems}

In the $\mathrm{Al}-\mathrm{C}$ system, a stoichiometric compound $\mathrm{Al}_{4} \mathrm{C}_{3}$ (D7 $7_{1}$-type rhombohedral) is known. The calculated Al-Co phase diagram [2004Oht] shows the following intermediate phases: CoAl (48-78.5 at.\% Co; B2, CsCl-type cubic), $\mathrm{Co}_{2} \mathrm{Al}_{5}$ (D8 $8_{11}$-type hexagonal), $\mathrm{CoAl}_{3}\left(D 0_{11}, \mathrm{Fe}_{3} \mathrm{C}\right.$-type

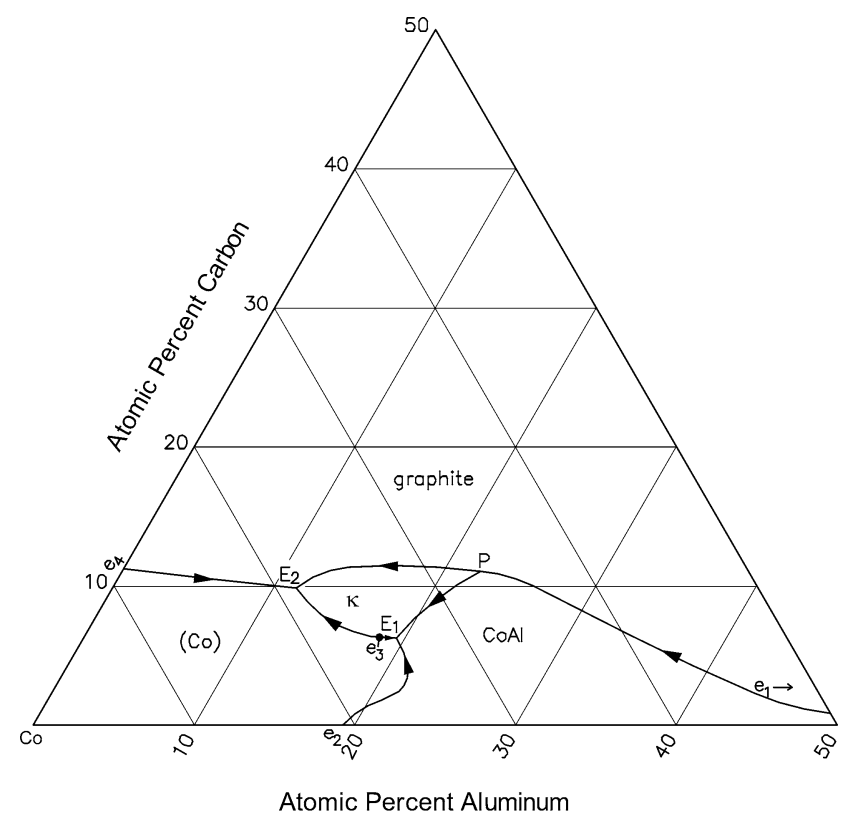

Fig. 1 Al-C-Co liquidus projection [2009Fri] orthorhombic), $\mathrm{Co}_{4} \mathrm{Al}_{13}$ (three crystal modifications), and

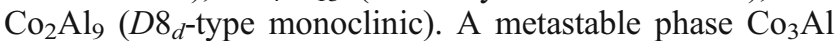
with the $L 1_{2}$-type of structure was suggested by [1995Kim], which is stabilized by $\mathrm{C}$ into the $E 2_{1}$-type compound $\mathrm{Co}_{3} \mathrm{AlC}_{x}(\kappa)$. The C-Co system is of the simple eutectic type, with the eutectic reaction at $1320{ }^{\circ} \mathrm{C}$.

\section{Ternary Phase Equilibria}

With starting metals of $99.998 \% \mathrm{Al}, 99.8 \% \mathrm{Co}$ and reactor grade graphite, [2009Fri] melted alloys in an alumina crucible under $\mathrm{Ar}$ atm. Differential thermal analysis was carried out at a heating/cooling rate of $5{ }^{\circ} \mathrm{C} / \mathrm{min}$. The phase equilibria were studied mainly with optical microscopy and x-ray powder diffraction. The main finding of [2009Fri] is a eutectic maximum on the univariant liquidus line $\mathrm{L}+(\mathrm{Co})+\mathrm{Co}_{3} \mathrm{AlC}_{x}$ at $1343{ }^{\circ} \mathrm{C}$ and at $18.6 \mathrm{Al}-6.25 \mathrm{C}$ (at.\%). The liquidus projection of [1995Kim] modified to include this eutectic maximum $\mathrm{e}_{3}$ is shown in Fig. 1.

\section{References}

1995Kim: Y. Kimura, M. Takahashi, S. Miura, T. Suzuki, and Y. Mishima, Phase Stability and Relations of Multi-Phase Alloys Based on B2-CoAl and $E 2_{1}-\mathrm{Co}_{3} \mathrm{AlC}_{x}$, Intermetallics, 1995, 3, p 413-425

2004Oht: H. Ohtani, M. Yamano, and M. Hasebe, Thermodynamic Analysis of the Co-Al-C and Ni-Al-C Systems by Incorporating ab initio Energetic Calculations into the CALPHAD Approach, CALPHAD, 2004, 28, p 177-190

2006Kim: Y. Kimura, K. Iida, F.G. Wei, and Y. Mishima, Phase Equilibria in the T-Al-C (T: Co, Ni, Rh, Ir) and T-Al-B (T: Rh, Ir) Systems for the Design of $E 2{ }_{1}-\mathrm{Co}_{3} \mathrm{AlC}$ Based Heat Resistant Alloys, Intermetallics, 2006, 14, p 508-514

2008Rag: V. Raghavan, Al-C-Co (Aluminum-Carbon-Cobalt), J. Phase Equilib. Diffus., 2008, 29(1), p 46-48

2009Fri: K. Fritscher and G.E. Welsch, Phase Relations in the Co-CoAl-C System Involving E2 $2_{1}$ Type $\mathrm{Co}_{3} \mathrm{AlC}_{x}$ Phase, Intermetallics, 2009, 17, p 427-434 